\title{
Immunization from a photographic perspective: the 1961 polio trial in Nova Scotia
}

$\mathrm{F}$ ifty years ago a team of doctors and nurses from the Nova Scotia Department of Health and Dalhousie University conducted what became known as the Wedgeport Polio Trial in which the oral trivalent Sabin vaccine was administered to an entire community in Southwest Nova Scotia. The results of the trial were published in this journal in $1962 ;{ }^{1} 50$ years on the trial is part of Canadian medical history. As CMAJ celebrates one hundred years of publishing medical research in Canada it is interesting to look at the trial from the perspective of the distinguished photojournalist, Bob Brooks, who accompanied the researchers on their rounds in March 1961.

Canada experienced great losses from paralytic polio epidemics in the 20th century. By 1934, almost half of Canada's disabled population could be linked to polio and in 1953, the year of the worst outbreak in Canadian history, almost 9000 cases were reported. While the injectable Salk vaccine helped control some of the epidemic, it did not stop all outbreaks, and more aggressive polio immunization campaigns were needed. Connaught Medical Laboratories, now Sanofi Pasteur, had been developing the trivalent Sabin vaccine (available at the time only in the United States), and this prompted field studies in Manitoba, Saskatchewan and Nova Scotia, which were pivotal in encouraging the licensing of the Sabin vaccine in Canada.

In Nova Scotia, Dr. C.E. van Rooyen, professor of bacteriology and associate provincial bacteriologist at Dalhousie University, and Dr. Vernon Rideout, director of the Western Nova Scotia Health Unit of the Provincial Department of Health, headed the team destined for Wedgeport, an Acadian fishing community in Yarmouth County. Wedgeport (with the neighbouring community of Comeau's Hill)

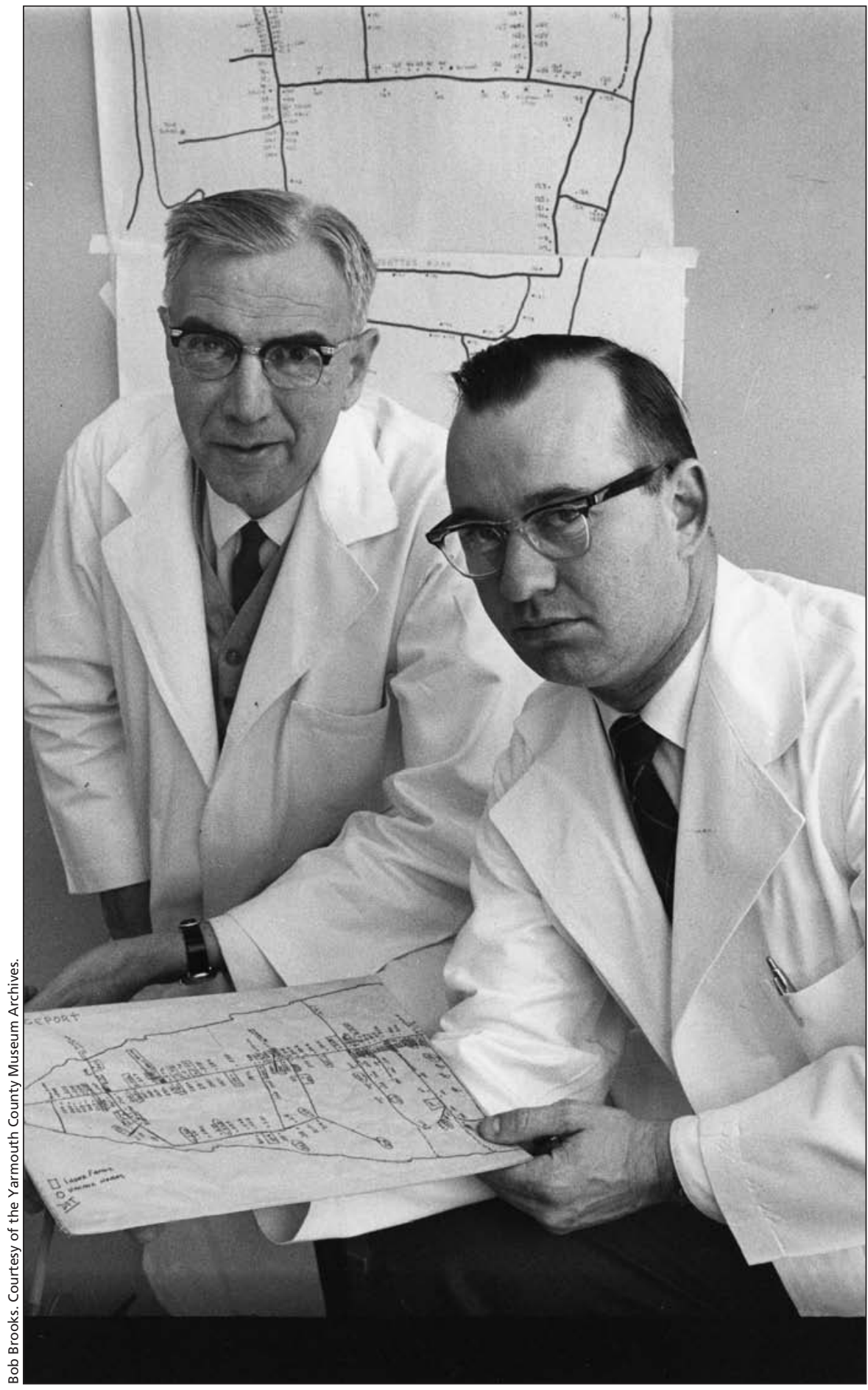

Dr. C.E. van Rooyen, professor of bacteriology at Dalhousie University [left] and Dr. Vernon Rideout, director of Public Health for Western Nova Scotia with a map of Wedgeport at the start of the trial. 


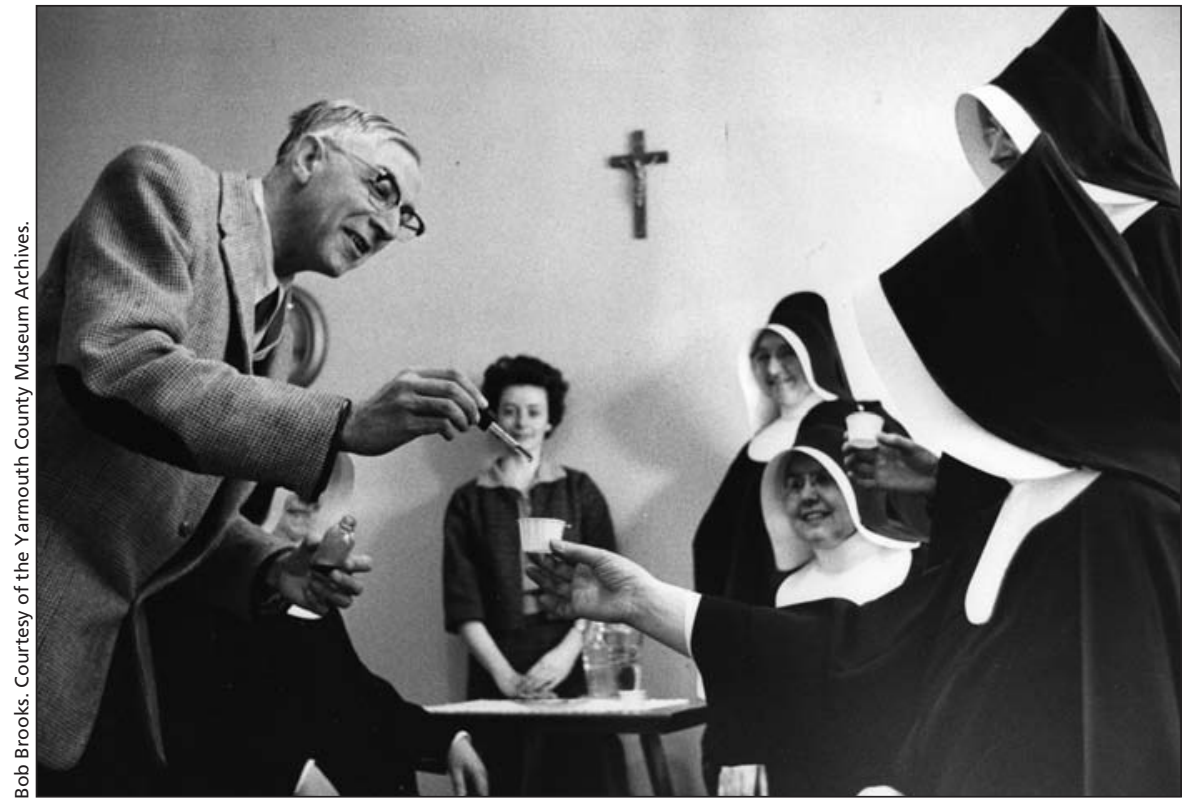

Dr. van Rooyen immunizes nuns from St. Michael's Convent, including Sisters Firma and Claude Colombière as registered nurse Doris LeBlanc looks on. was chosen for several reasons: it is a static and relatively isolated community perfect for epidemiological study, the previous health of the district had been good and polio-free for 20 years and the public health immunization records were readily available. The objectives were to study any illness occurring after vaccination, to compare antibody level against polio before and after vaccination, to search the area for the possible presence of enteroviruses which might interfere with gut infection, to correlate excretion of vaccine virus with Salk status, antibody level, and age, and to determine whether vaccine poliovirus would spread to surrounding communities.

In addition to van Rooyen and Rideout, the team included Drs. Rudy Ozere, Horace B. Colford, as well as local doctors, Milton O'Brien and W.C.

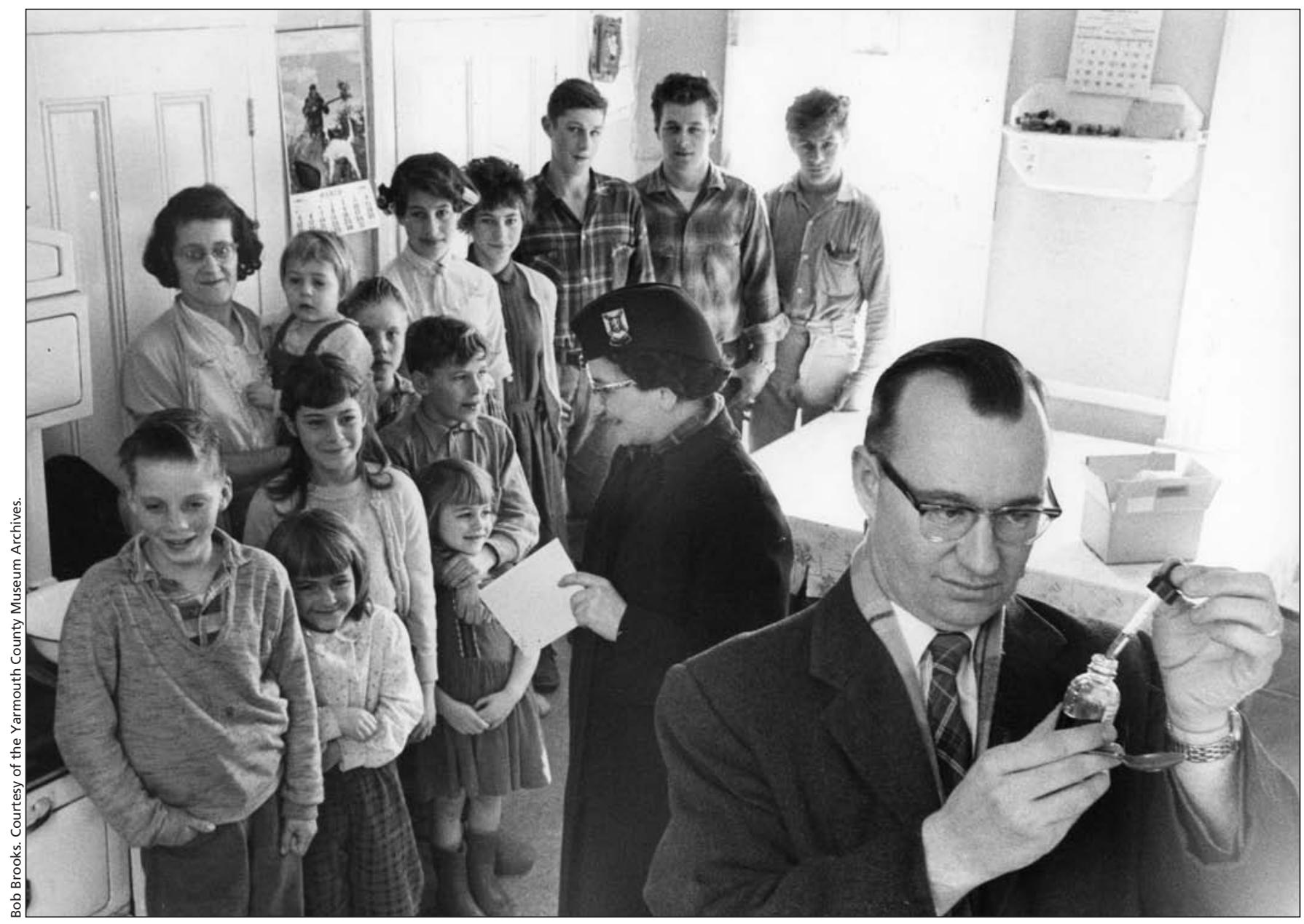

Twelve of the 15 children in this Nova Scotia family await vaccination. This family was 1 of 20 index families who agreed to more extensive testing. Talking to the children is public health nurse Cécile Amirault while Dr. Rideout measures the dose. 
O'Brien. The compliance of the community was due in part to the cooperation of St. Michael's Parish. With the aim of obtaining complete family participation, all age groups received the vaccine, ranging from a week-old infant to a 96-year-old woman. A total of 1692 people were offered the vaccine; $97.1 \%$ were ultimately vaccinated. Results of the trial indicated there were no ill effects attributable to the vaccine either during or after the vaccination period. ${ }^{1}$ In the summer months following the trial, no cases of poliomyelitis were reported in Western Nova Scotia. As a result of the Wedgeport polio trial as well as the sister demonstrations in Manitoba and Saskatchewan, the oral trivalent Sabin vaccine was licensed in Canada in March 1962.

Bob Brooks (1927-1999) was a distinguished Nova Scotia photojournalist who, in the course of his career, received more than 40 international photography awards. His photographs appeared in more than 30 publications including National Geographic, Harper's and The London Times, as well as in several books, including his own work Yarmouth County. He also covered some controversial news stories including the 1962 decision of the

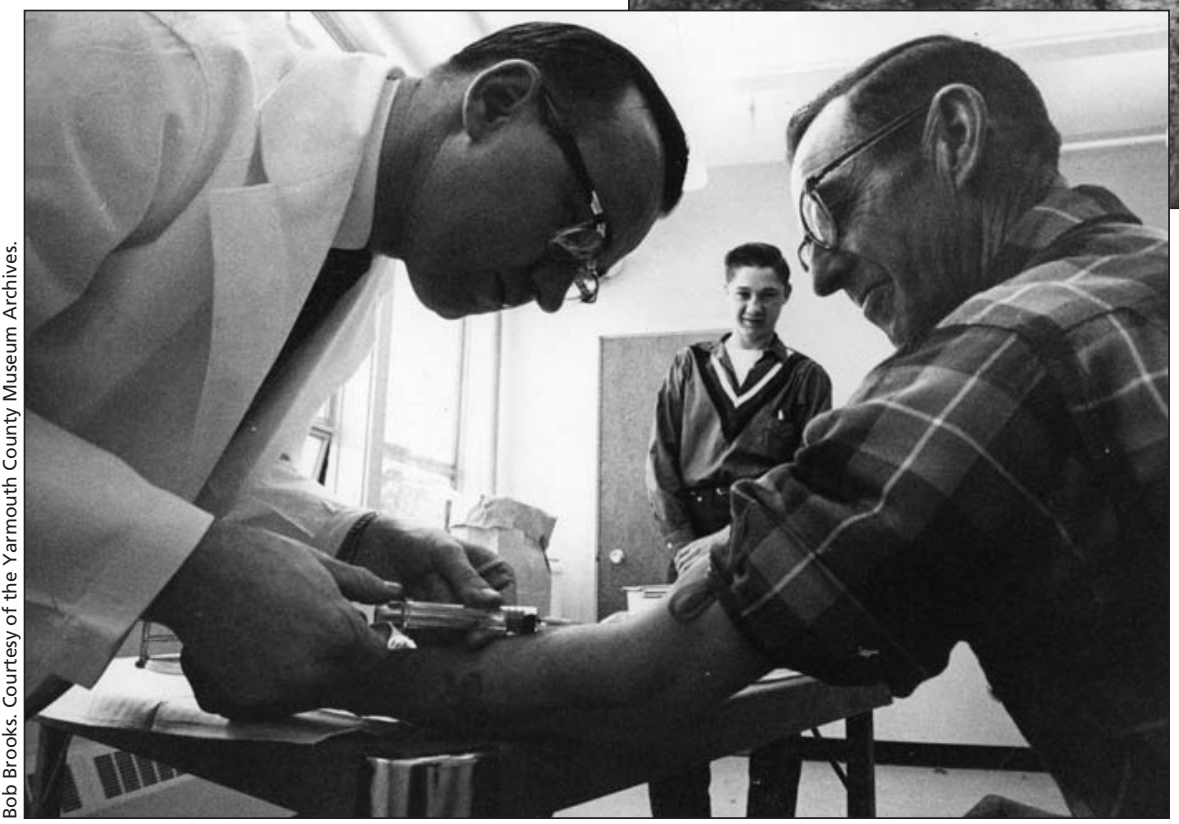

Dr. Rudy Ozere, professor of Pediatrics at Dalhousie University, and one of the registered nurses making their way down a muddy track in Comeau's Hill. The caption in Dr. Rideout's photo album stated: "Did someone say muddy? It was me and Dr. Ozere."

Dr. Rideout takes blood from Henry Boudreau, lobster and tuna fisherman, as Delbert Pothier looks on. 


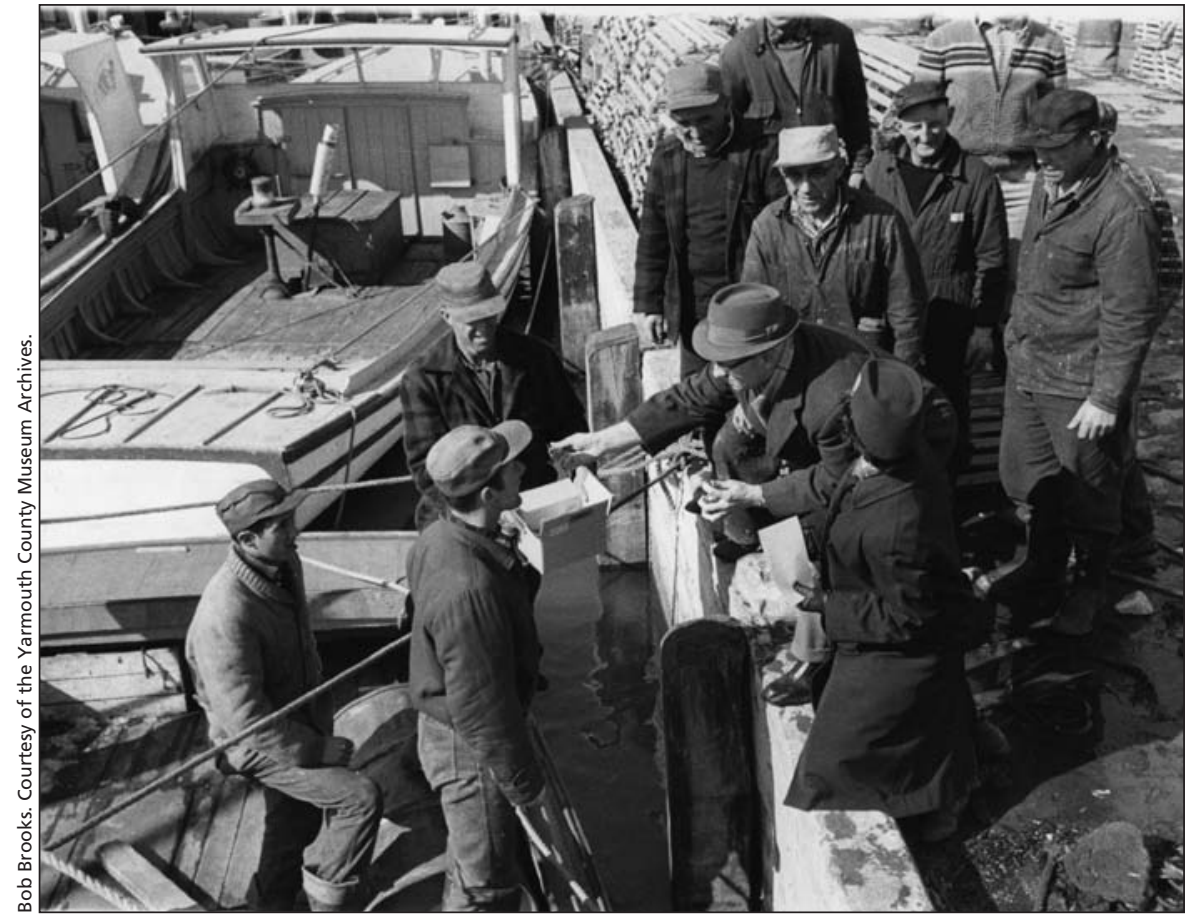

Fishermen returning from the lobster grounds found Dr. Rideout and public health nurse Cécile Amirault at the Tuna Wharf waiting for them. The caption in Dr. Rideout's album stated: "Steady now or someone will fall in." city of Halifax to demolish the Black community of Africville and in 1964 he accompanied Canadian Peacekeepers to Cyprus on the HMCS Bonaventure for The Star Weekly. Brooks died in 1999.

In 1961, he accompanied the physicians and nurses in Wedgeport and Comeau's Hill to document the immunization campaign. In a 48-hour period beginning on Mar. 4, 1961, doctornurse teams, and Bob Brooks, trudged to homes, shops, and wharves in Wedgeport and Comeau's Hill. The result was a series of remarkable black and white photographs. Brooks had a wonderful eye for composition and in combination with that stark, unforgiving palette he captured the bleak coastal landscape in late winter and the goodnatured cooperation of this fishing community; his work was honest and unemotional, but not without an occasional touch of humour.

Individual photographs from this series were subsequently published in

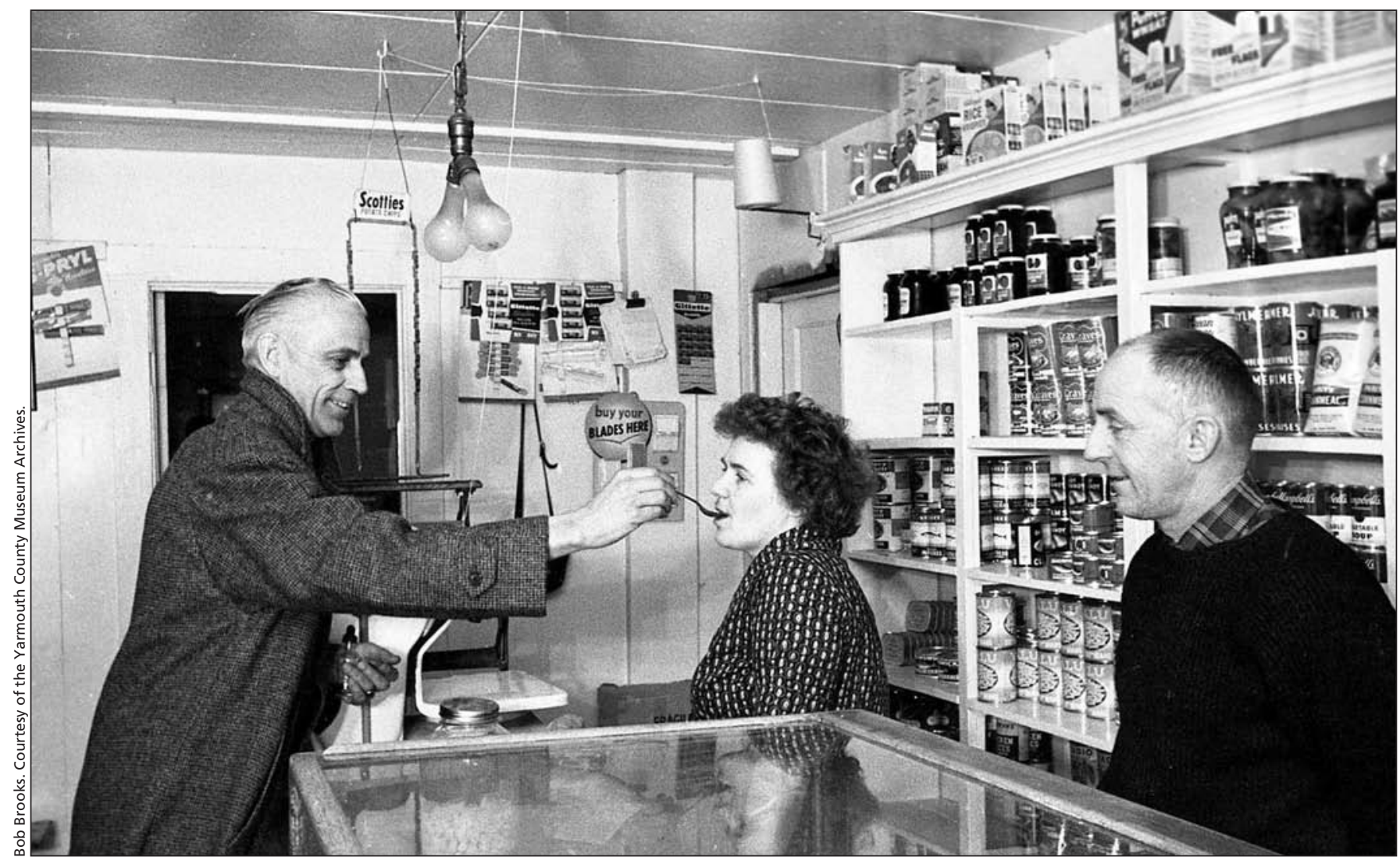

Dr. Horace B. Colford, director of Child and Maternal Health and Communicable Disease Control at the Nova Scotia Department of Health, immunizes Mr. and Mrs. Edmund LeBlanc in their well-stocked shop in Lower Wedgeport. 


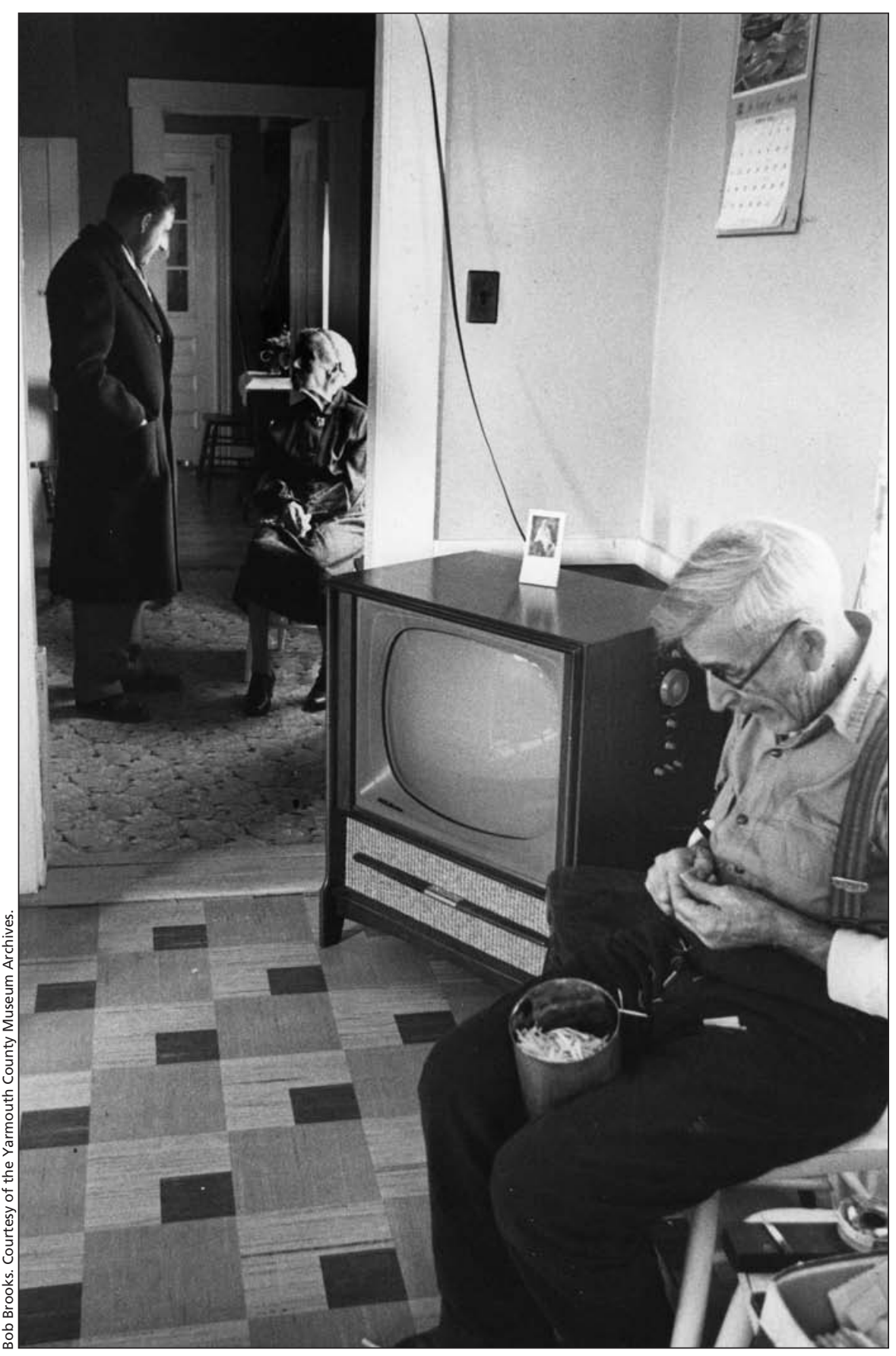

Dr. Ozere in conversation with 96-year-old Marie-Jeanne Pothier. In the foreground, Levi Meuse whittles lobster pegs. The caption in Dr. Rideout's album stated: "Not even Sabin vaccine interferes with my peg-making."

the local press and the series was included in a retrospective of Brooks's work at the Yarmouth County Museum in 1994. In the second half of April 2011, which is the 50th anniversary of the trial, 20 of these photographs will be exhibited at the Yarmouth Regional Hospital.
A recent editorial in the Nova Scotia Policy Review ${ }^{3}$ contrasted Brooks's work with the type of photojournalism currently practiced in the province, declaring that, "his photographs display the human face of policy decisions malevolent and benevolent." With reference to the Wedgeport photographs,

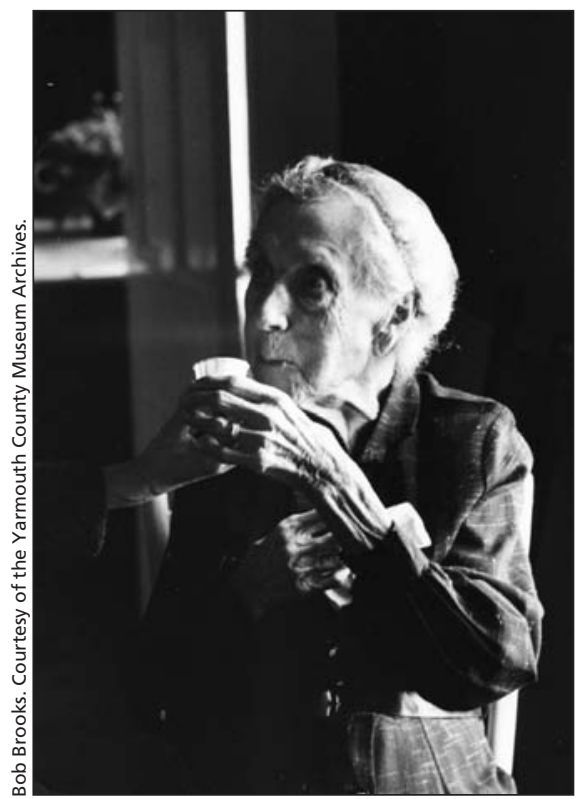

Mme Marie-Jeanne Pothier wore her good dress for the occasion.

the editor continued, "If these same events were unfolding today, images like these would give us greater insight into how such decisions affect people for good or for ill."

\section{Rosalind Ashton BA\&Sc}

Class of 2012

Medical School

Dalhousie University

Halifax, NS

Susan H. Young PhD

Western Counties Regional Library

Yarmouth, NS

\section{References}

1. van Rooyen CE, Rideout V, Ozere RL, et al. Oral vaccination against poliomyelitis: report of a field trial at Wedgeport, Nova Scotia, Can Med Assoc J 1962; 86:1185-91. Available: www.cmaj.ca/100/pdfs/oral _vaccination_against_poliomyelitis.pdf (accessed 2011 Mar. 15)

2. Rutty CJ, Barreto L, Van Exan R, et al. Conquering the crippler: Canada and the eradication of polio Can J Public Health 2005;96:I1-I24.

3. Brighton R. Human documents. Nova Scotia Policy Review 2008;2:2-3

Acknowledgements: Permission to reproduce the photographs illustrating this article was kindly given by the Yarmouth County Museum Archives and the authors would like to acknowledge the assistance of the archivist, Jamie Serran. Brooks donated his negatives pertaining to events in the County to the Yarmouth County Museum and Archives, which also holds Dr. Vernon Rideout's souvenir photograph album containing 21 photographs with captions.

CMAJ 2011. DOI:10.1503/cmaj.110286 